\title{
Review Article \\ Subarachnoid Hemorrhage, Spreading Depolarizations and Impaired Neurovascular Coupling
}

\author{
Masayo Koide, ${ }^{1}$ Inna Sukhotinsky, ${ }^{2,3}$ Cenk Ayata, ${ }^{2}$ and George C. Wellman ${ }^{1}$ \\ ${ }^{1}$ Department of Pharmacology, University of Vermont College of Medicine, Burlington, VT 05405-0068, USA \\ ${ }^{2}$ Neurovascular Research Laboratory, Department of Radiology, Stroke Service and Neuroscience Intensive Care Unit, \\ Department of Neurology, Massachusetts General Hospital and Harvard Medical School, Boston, MA 02115, USA \\ ${ }^{3}$ Gonda Multidisciplinary Brain Research Center, Bar-Ilan University, Ramat-Gan 52990, Israel
}

Correspondence should be addressed to George C. Wellman; gwellman@uvm.edu

Received 27 December 2012; Accepted 8 February 2013

Academic Editor: Ryszard M. Pluta

Copyright (C) 2013 Masayo Koide et al. This is an open access article distributed under the Creative Commons Attribution License, which permits unrestricted use, distribution, and reproduction in any medium, provided the original work is properly cited.

\begin{abstract}
Aneurysmal subarachnoid hemorrhage (SAH) has devastating consequences on brain function including profound effects on communication between neurons and the vasculature leading to cerebral ischemia. Physiologically, neurovascular coupling represents a focal increase in cerebral blood flow to meet increased metabolic demand of neurons within active regions of the brain. Neurovascular coupling is an ongoing process involving coordinated activity of the neurovascular unit—neurons, astrocytes, and parenchymal arterioles. Neuronal activity can also influence cerebral blood flow on a larger scale. Spreading depolarizations (SD) are self-propagating waves of neuronal depolarization and are observed during migraine, traumatic brain injury, and stroke. Typically, $\mathrm{SD}$ is associated with increased cerebral blood flow. Emerging evidence indicates that SAH causes inversion of neurovascular communication on both the local and global level. In contrast to other events causing SD, SAH-induced SD decreases rather than increases cerebral blood flow. Further, at the level of the neurovascular unit, SAH causes an inversion of neurovascular coupling from vasodilation to vasoconstriction. Global ischemia can also adversely affect the neurovascular response. Here, we summarize current knowledge regarding the impact of SAH and global ischemia on neurovascular communication. A mechanistic understanding of these events should provide novel strategies to treat these neurovascular disorders.
\end{abstract}

\section{Pathophysiology of Subarachnoid Hemorrhage}

Aneurysmal subarachnoid hemorrhage (SAH) is associated with high morbidity and mortality with limited therapeutic options [1]. The major contributor to poor outcome of patients surviving the initial surge in intracranial pressure is delayed cerebral ischemia (DCI) manifesting 4-10 days after aneurysm rupture as new and otherwise unexplained neurological deficits and/or ischemic lesions within the brain [2]. Despite decades of study, mechanisms contributing to SAHinduced DCI remain controversial. For many years, a delayed and prolonged vasospasm of large conduit arteries was thought to be the major contributor to DCI and the ensuing death and disability observed in SAH patients [3, 4]. Recent data, however, challenge this view [5-7] and strongly suggest that additional mechanisms contribute to poor outcomes after $\mathrm{SAH}$, including early brain injury suffered at the time of bleed [6, 8-10], blood-brain barrier disruption [11, 12], inflammation [13-15], and impaired microcirculatory function [16-19]. Evidence suggests that a pathological inversion of neurovascular coupling may play an important role in $\mathrm{SAH}$ pathology both in the context of spreading depolarization waves [20] and at the level of the neurovascular unit in response to focal neuronal activity [21].

\section{Spreading Depression and Injury Depolarizations}

Spreading depression (SD) is the historical term used to describe intense neuronal and glial depolarization events that propagate within cortical or subcortical grey matter at a rate of $2-4 \mathrm{~mm} / \mathrm{min}$ regardless of functional divisions or arterial 
boundaries [22]. Initially implicated in migraine aura, SDlike depolarization waves also occur in stroke and traumatic brain injury $[23,24]$. The pivotal event during SD is a massive $\mathrm{K}^{+}$efflux that increases extracellular $\mathrm{K}^{+}$concentration to $>40 \mathrm{mM}$. Massive influx of $\mathrm{Ca}^{2+}, \mathrm{Na}^{+}$, and water accompanies the $\mathrm{K}^{+}$efflux and triggers uncontrolled release of neurotransmitters, most importantly the excitatory amino acid glutamate. Released $\mathrm{K}^{+}$and glutamate are believed to depolarize other neurons in the vicinity, and SD slowly propagates in grey matter by way of contiguity. Therefore, extracellular medium, including the perivascular space, is flooded with $\mathrm{K}^{+}$ and neurotransmitters that are vasoactive. Because complete membrane depolarization precludes action potentials and synaptic transmission, SD is associated with suppression of all spontaneous or evoked electrical activity. Consequently, the normal neuronal influence on the vasculature is absent at least until the ability of neurons to generate action potentials returns, which can take several minutes. Moreover, there is ample evidence suggesting that physiological neurovascular coupling is impaired not only during the depolarization but for hours after the SD event [25-28].

$\mathrm{SD}$ is triggered when a minimum critical volume of brain tissue is simultaneously depolarized. Therefore, cerebral ischemia, anoxia, and other forms of brain injury can all trigger SD. Both animal models and clinical studies have clearly demonstrated the occurrence of SD waves associated with traumatic brain injury, cerebral ischemia, and subarachnoid hemorrhage [24, 29-33]. With respect to the emergence of SD after SAH, a number of potentially interacting factors have been implicated. These SD promoting factors and influences from subarachnoid blood include increased extracellular $\mathrm{K}^{+}$ combined with decreased nitric oxide bioavailability [30, 34, 35], oxyhemoglobin [34, 36, 37], and endothelin-1 [37-40]. Such spreading injury depolarizations occur repetitively over hours and days and propagate throughout the unhealthy, but not yet depolarized or necrotic tissue (e.g., ischemic penumbra). Indeed, such injury depolarizations are indistinguishable from SD when they often propagate into noninjured tissue. The existence of injury depolarizations has been recognized for decades, and their detrimental effect on tissue outcome has been attributed to their profound metabolic impact. More recently, however, an additional mechanism was discovered that exacerbates the energy supply-demand mismatch in injured brain. This novel mechanism, termed inverse or vasoconstrictive neurovascular coupling, leads to a reduction in tissue perfusion instead of the usual hyperemia $\mathrm{SD}$ causes in normal brain tissue.

\section{Influence of Spreading Depolarizations on Cerebral Blood Flow}

In most species and studies, and under normal physiological conditions, SD is typically associated with a profound hyperemic response that starts shortly after the onset of depolarization and outlasts it by a few minutes [41-46]. As SD has a profound metabolic impact on brain tissue [47], this increase in the flow of nutrients enables neurons to recover from the massive ion and water imbalance occurring during $\mathrm{SD}$ events. However, the vasomotor impact of SD can also be complex. For example, a brief hypoperfusion occasionally precedes the hyperemia, its onset coinciding with the onset of depolarization. This initial hypoperfusion is augmented by nitric oxide (NO) inhibition, particularly when extracellular potassium $\left(\left[\mathrm{K}^{+}\right]_{\mathrm{e}}\right)$ is artificially elevated $[34,48-51]$. In mice, the initial vasoconstriction is much more pronounced and hyperemia is completely absent [41]. Vascular response also appears to vary depending on vessel caliber and/or cortical depth. Larger pial surface arterioles respond to SD with a small initial constriction followed by dilation, whereas smaller parenchymal arterioles mainly constrict [52]. In general, vasoconstrictive tone develops during the depolarization, followed by a vasodilator tone during repolarization, and then a second vasoconstrictive phase that can last up to an hour [53]. The magnitude and time course of these opposing vasomotor components vary depending on species and experimental conditions, can be modulated physiologically and pharmacologically, and determine the final morphology of the hemodynamic response [53]. Altogether, these observations suggest that $\mathrm{SD}$ exerts multiple opposing vasomotor effects on blood vessels, with vasodilation predominating in healthy tissue.

Pathological circumstances such as ischemic stroke or subarachnoid hemorrhage modulate the magnitude and timing of the vasomotor components. Under such conditions, the vascular response becomes predominantly vasoconstrictive, that is, inverted $[46,54,55]$. This likely represents a shift in the balance of vasomotor influences to vasoconstriction. As a result, injury depolarizations cause hypoperfusion rather than hyperemia that could potentially lead to a downward spiral of increased brain injury $[33,56,57]$. In ischemic penumbra, the more ischemic the tissue is (i.e., closer to the core), the more severe the vasoconstrictive component becomes [33, 56, 58-60]. Such conditions can be recreated to transform the $\mathrm{CBF}$ response. For example, in the presence of extravascular hemoglobin and elevated $\left[\mathrm{K}^{+}\right]_{\mathrm{e}}$ or low glucose, mimicking subarachnoid hemorrhage, SD is associated with severe vasoconstriction [34]. Induced hypoxia and hypotension independently augment the hypoperfusion component of the hemodynamic response to SD and significantly diminish the hyperemia [61]. Although hypotension appears to be more potent than hypoxia in this regard, combined hypoxia and hypotension, most closely mimicking ischemic penumbra, transforms the predominantly dilator response into a biphasic one. Neither induced hyperoxia nor hyperglycemia restores the CBF response [55, 62], suggesting that cerebral perfusion pressure affects SD-mediated vascular responses by a mechanism unrelated to tissue energy status.

Despite the fact that SD in normal cortex is not damaging, this severe vasoconstrictive response can lead to injury and cell death, even in the absence of any preexisting energy depletion [36]. Indeed, injury depolarizations worsen tissue and neurological outcome in focal cerebral ischemia and other brain injury states including aneurysmal SAH [20, 29, $31,57,63]$. Conversely, drugs that are known to inhibit cortical spreading depression, such as NMDA receptor antagonists MK-801, diminish the severity of episodic hypoperfusions and prevent the expansion of severely hypoperfused cortex, eventually reducing the infarct size $[20,29,31,33,63]$. 
However, in vivo studies have shown the efficacy of MK-801 to prevent $\mathrm{SD}$ was greatly diminished when extracellular $\mathrm{K}^{+}$was elevated [64]. Topical application of vasodilator agents such as nitric oxide and the L-type voltage-dependent $\mathrm{Ca}^{2+}$ channel blocker nimodipine reverts the vasoconstrictive response to vasodilation $[34,54,65]$. Therefore, mechanisms transforming the $\mathrm{CBF}$ response from hyperemia to hypoperfusion during injury depolarizations may be targeted to interrupt the vicious cycle and improve tissue outcome. Further, recent evidence suggests SAH can have a profound impact on the individual neurovascular unit leading to inversion of neurovascular coupling in the absence of SD.

\section{Functional Hyperemia at the Level of the Neurovascular Unit}

Functional hyperemia and neurovascular coupling are terms often used interchangeably to describe increased cerebral blood flow $(\mathrm{CBF})$ in brain regions with enhanced neuronal activity, which forms the basis of functional magnetic resonance imaging (fMRI) [66]. This localized vasodilation to meet activity-dependent metabolic demand involves interplay of cells comprising the neurovascular unit-neurons, astrocytes and intracerebral (parenchymal) arterioles [6769]. Astrocytes act as key intermediaries in the neurovascular response, structurally having close "synapse-like" associations with neurons as well as processes (astrocytic endfeet) that completely encase parenchymal arterioles. Over the past decade, numerous investigators primarily using cortical brain slices have provided evidence linking increased neuronal activity and nerve-mediated glutamate release to the activation of astrocytic metabotropic glutamate receptors (mGluRs), inositol triphosphate- $\left(\mathrm{IP}_{3}^{-}\right)$mediated increase in astrocyte $\mathrm{Ca}^{2+}$ and $\mathrm{Ca}^{2+}$-dependent release of vasodilator influences from astrocytic endfeet $[68,70-75]$. Excitatory and inhibitory interneurons may also modulate the neurovascular coupling process via an influence on astrocyte $\mathrm{Ca}^{2+}$ or through direct effects on parenchymal arterioles [7678]. Multiple vasodilator mechanisms have been proposed to contribute neurovascular coupling. Elevations in astrocytic endfoot $\mathrm{Ca}^{2+}$ have been linked to increased $\mathrm{Ca}^{2+}$-dependent phospholipase $\mathrm{A}_{2}\left(\mathrm{PLA}_{2}\right)$ activity and release of vasodilatory arachidonic acid metabolites. These include prostaglandin $\mathrm{E}_{2} \quad\left(\mathrm{PGE}_{2}\right)$ produced by cyclooxygenase-1, and epoxyeicosatrienoic acids (EETs) produced by the cytochrome P450 epoxygenase, CYP 2C11 [70, 71, 79-81]. In addition, large conductance $\mathrm{Ca}^{2+}$-activated $\mathrm{K}^{+}(\mathrm{BK})$ channels are localized to astrocytic endfeet [82] and play a key role in neurovascular coupling $[69,83,84]$. Endfoot BK channel activation by moderate increases in astrocytic $\mathrm{Ca}^{2+}$ causes localized increases in $\mathrm{K}^{+}$in the perivascular space that stimulate inwardly rectifying $\mathrm{K}^{+}\left(\mathrm{K}_{\mathrm{ir}}\right)$ channels located on the smooth muscle of parenchymal arterioles leading to membrane potential hyperpolarization and vasodilation [69, 71, 75, 83-85]. In sum, increased endfoot $\mathrm{Ca}^{2+}$ is a critical step linking local neuronal activity to parenchymal arteriolar dilation.

\section{Neurovascular Coupling Can Also Lead to Pathological Vasoconstriction}

In vitro studies have reported that under certain conditions, neuronal activation can also lead to parenchymal arteriolar constriction [84, 86-88]. Neurally evoked vasoconstriction likely represents a pathological phenomenon promoting a decrease, rather than an increase in blood flow to metabolically active brain tissue. Mulligan and MacVicar [88] were the first to report this phenomenon in brain slices using the neurotransmitter norepinephrine or the release of caged $\mathrm{Ca}^{2+}$ to increase $\mathrm{Ca}^{2+}$ levels in the astrocyte soma. These constrictions were abolished by blockers of $\mathrm{Ca}^{2+}$-sensitive $\mathrm{PLA}_{2}$ activity and the CYP4a-mediated metabolism of arachidonic acid to the vasoconstrictor 20-hydroxyeicosatetraenoic acid (20-HETE). Both neurally mediated vasodilation and vasoconstriction have been observed in the retina [87]. In the retina, the balance between constriction and dilation was dependent upon nitric oxide (NO) levels, with 20-HETE synthesis contributing to constriction. Work by Girouard et al. [84] demonstrated that the level of astrocytic endfoot $\mathrm{Ca}^{2+}$ and endfoot BK channel activity dictate the polarity of the diameter changes caused by neuronal stimulation in cortical brain slices. These investigators observed that modest increases in endfoot $\mathrm{Ca}^{2+}(<500 \mathrm{nM})$ and endfoot BK channel activity lead to enhanced arteriolar $K_{\text {ir }}$ activity, membrane potential hyperpolarization, and vasodilation. However, more robust elevations in endfoot $\mathrm{Ca}^{2+}(>500 \mathrm{nM})$ lead to sufficient $\mathrm{BK}$ channel-mediated $\mathrm{K}^{+}$efflux from endfeet causing arteriolar smooth muscle membrane potential depolarization and constriction. Further, modest elevation of bulk extracellular $\mathrm{K}^{+}$also caused inversion of neurovascular coupling from vasodilation to vasoconstriction. Thus, several factors including astrocyte endfoot $\mathrm{Ca}^{2+}$ levels, extracellular $\mathrm{K}^{+}$ concentration and endfoot $\mathrm{BK}$ channel activity can influence the polarity and amplitude of the neurovascular response.

\section{Inversion of Neurovascular Coupling from Vasodilation to Vasoconstriction after Subarachnoid Hemorrhage}

To examine the impact of experimental SAH on neurovascular coupling, our laboratory has used a combination of multiphoton confocal imaging and infrared-differential interference contrast (IR-DIC) microscopy to simultaneously measure astrocytic endfoot $\mathrm{Ca}^{2+}$ and parenchymal arteriolar diameter in cortical brain slices from SAH model rats [21]. Neurovascular responses were evoked using electrical field stimulation (EFS) of neurons using parameters that did not directly affect astrocytes or parenchymal arterioles. In brain slices from control and sham-operated animals, neuronal activation caused the anticipated increase in astrocytic endfoot $\mathrm{Ca}^{2+}$ and vasodilation. This vasodilation was greatly diminished by paxilline, a BK channel blocker, consistent with involvement of endfoot $\mathrm{BK}$ channels $[69,83,84]$. In marked contrast, a similar level of neuronal activation and elevation in endfoot $\mathrm{Ca}^{2+}$ caused vasoconstriction rather 
than vasodilation in brain slices from SAH model animals (Figure 1). This SAH-induced shift in neurovascular coupling from vasodilation to vasoconstriction likely represents a pathological response that could locally limit blood flow to cortical regions and was not due to increased 20-HETE or prostaglandin production. However, neurally evoked vasoconstriction after SAH was abolished by block of endfoot BK channels. Our evidence suggests the inversion of neurovascular coupling after SAH is due to increased basal endfoot BK channel activity and increased $\mathrm{K}^{+}$in the restricted perivascular space between astrocytic endfeet and parenchymal arteriolar smooth muscle. This abnormal elevation of basal perivascular $\mathrm{K}^{+}$combined with "normal" BK channel-mediated $\mathrm{K}^{+}$efflux stimulated by neuronal activity elevates $\mathrm{K}^{+}$above the dilation/constriction threshold, switching the polarity of arteriolar responses to vasoconstriction. Consistent with this interpretation, increasing concentrations of extracellular $\mathrm{K}^{+}$ elicit a bimodal response in isolated parenchymal arterioles $[21,83,84]$. Modest increases in $\mathrm{K}^{+}(<20 \mathrm{mM})$ induce smooth muscle hyperpolarization and arteriolar dilation through activation of $\mathrm{K}_{\mathrm{ir}}$ channels expressed on arteriolar myocytes [89]. However, $\mathrm{K}^{+}$increases greater than $\sim 20 \mathrm{mM}$ cause a depolarizing shift in the $\mathrm{K}^{+}$equilibrium potential $\left(\mathrm{E}_{\mathrm{K}}\right)$ sufficient to increase the activity of voltage-dependent $\mathrm{Ca}^{2+}$ channels leading to enhanced $\mathrm{Ca}^{2+}$ influx and vasoconstriction. Although the vascular responses are inverted after SAH, both neurovascular responses (i.e., vasodilation in control animals and vasoconstriction in $\mathrm{SAH}$ animals) involve the same mechanistic elements: elevated astrocytic endfoot $\mathrm{Ca}^{2+}$ and $\mathrm{K}^{+}$efflux mediated by endfoot BK channels with the polarity of the vascular response dictated by basal perivascular $\mathrm{K}^{+}$ levels.

Our data also indicate fundamental changes in the resting activity of astrocyte $\mathrm{Ca}^{2+}$ signaling underlying $\mathrm{SAH}$-induced elevation in basal perivascular $\left[\mathrm{K}^{+}\right]$, leading to inversion of neurovascular coupling. In addition to responding to neurally released signals, astrocytes exhibit spontaneous $\mathrm{Ca}^{2+}$ oscillations [90]. These $\mathrm{Ca}^{2+}$ oscillations occur in both soma and endfeet and have been observed in isolated brain slices $[90,91]$ and in vivo [92-94]. This spontaneous activity occurs in the presence of $\mathrm{Na}^{+}$channel blocker tetrodotoxin to inhibit neuronal action potentials and represent intracellular $\mathrm{Ca}^{2+}$ release events from the endoplasmic reticulum [91]. An increase in the frequency of spontaneous astrocytic $\mathrm{Ca}^{2+}$ events in mouse models of Alzheimer's disease has been linked to vascular instability in vivo [94]. In brain slices from SAH model animals, we observed a marked increase in the amplitude of these events [21] (Figure 2). After SAH, the mean peak amplitude of spontaneous $\mathrm{Ca}^{2+}$ oscillations in astrocyte endfeet was $\sim 490 \mathrm{nM}$ compared to a mean peak amplitude $\sim 320 \mathrm{nM}$ in brain slices from control animals. In comparison, neurally-evoked increases in astrocytic $\mathrm{Ca}^{2+}$ were $\sim 350 \mathrm{nM}$ in both control and SAH animals. Considering that EFSinduced increases in astrocytic endfeet $\mathrm{Ca}^{2+}$ have been shown to induce $\mathrm{K}^{+}$efflux through endfoot $\mathrm{BK}$ channels, spontaneous $\mathrm{Ca}^{2+}$ events are also likely capable of activating endfoot $\mathrm{BK}$ channels. Based on these observations, it is conceivable that higher amplitude spontaneous $\mathrm{Ca}^{2+}$ events following
SAH enhance BK channel activity contributing to increased basal $\mathrm{K}^{+}$in restricted perivascular space (Figure 3 ). Factors leading to higher amplitude spontaneous $\mathrm{Ca}^{2+}$ events after SAH are not currently known; however, determining their identity will provide valuable new information in the search for finding new therapeutic strategies to help SAH patients.

\section{Impact of Global Ischemia on Neurovascular Coupling}

Global cerebral ischemia represents a generalized reduction in brain blood flow caused by, for example, cardiac arrest, shock, asphyxia, and strokes including SAH. The impact of global ischemia on brain function can range from relatively mild and temporary cognitive impairment to brain death, depending on the severity and length of the ischemic insult. Multiple mechanisms have been implicated in neuronal injury caused by global cerebral ischemia including neurotransmitter (e.g., glutamate) toxicity, cortical spreading depression, inflammation, and apoptosis [95]. Emerging evidence indicates that global ischemia may also influence neurovascular coupling. In rats, moderate, temporary forebrain ischemia can be achieved by a combination of bilateral carotid artery occlusion and controlled hypotension via the withdrawal of blood. Using this approach, Zhou et al. [96] examined the impact of 15 minutes of ischemia and reperfusion on the ability of whisker stimulation to increase relative cerebral blood flow (rCBF) to the somatosensory cortex using laser speckle imaging. Prior to the ischemic insult, $\mathrm{rCBF}$ to the somatosensory cortex increased $\sim 10 \%$ in response to whisker stimulation. Following ischemia and 20 minutes of reperfusion, increased $\mathrm{rCBF}$ to whisker stimulation was slightly diminished and response time increased; responses returned to preischemic levels within two hours. Recently, Baker et al. examined varying levels of global forebrain ischemia on the ability of forepaw stimulation to increase cerebral blood flow in the somatosensory cortex of rats [97]. Neurovascular coupling was attenuated with increasing levels of ischemia, with severe ischemia (60\% reduction in global cerebral blood flow) causing greater than a $90 \%$ reduction in the neurovascular response. The attenuation of neurovascular coupling associated with severe global ischemia lasts for several days following reperfusion [98]. Currently, little information is available regarding the cellular mechanisms contributing to decreased neurovascular coupling associated with global ischemia. However, it is likely that ischemia may impact more than one component of the neurovascular unit. For example, ischemia has been shown to impair cerebral artery function that may limit vasodilation $[99,100]$. Further, global ischemia has been shown to alter expression of $\mathrm{K}^{+}$-selective ion channels and TRPV4 nonselective cation channels in astrocytes from rat hippocampus [101, 102].

Global cerebral ischemia may also contribute to brain pathologies associated with SAH. Immediately following cerebral aneurysm rupture, increased intracranial pressure caused by the release of blood into the subarachnoid space can lead to transient global ischemia and contribute to a cascade of events referred to as "early brain injury" $[6,10]$. 

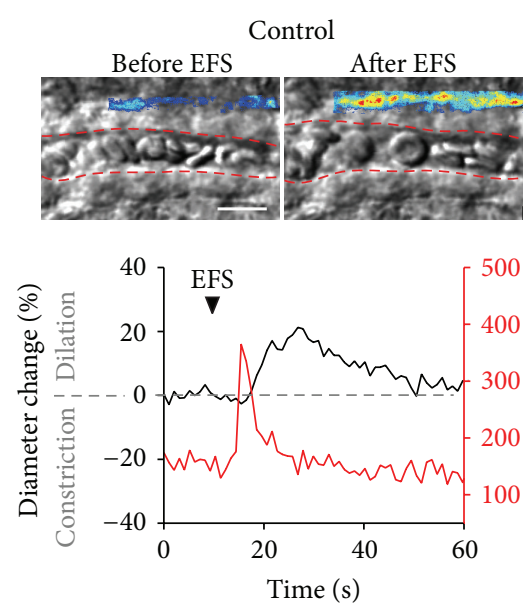
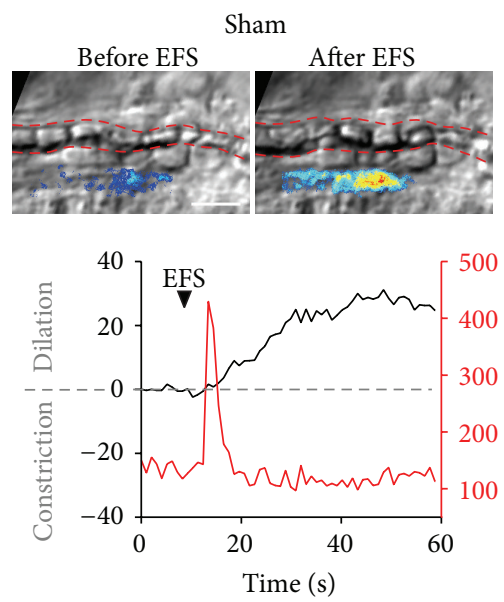
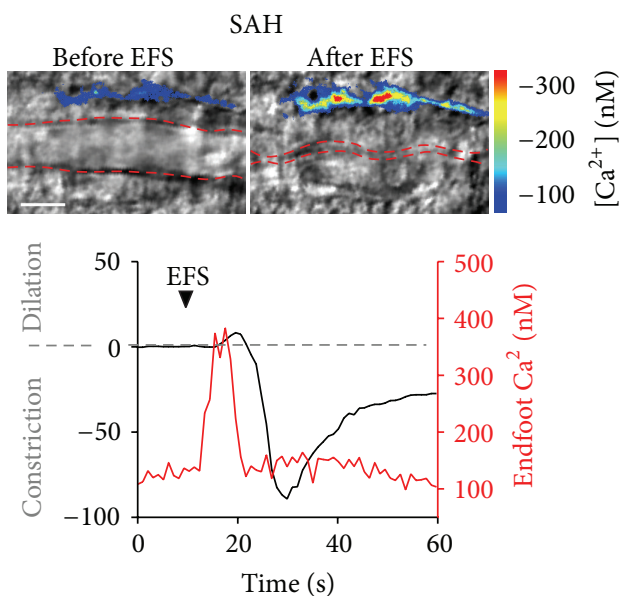

(a)

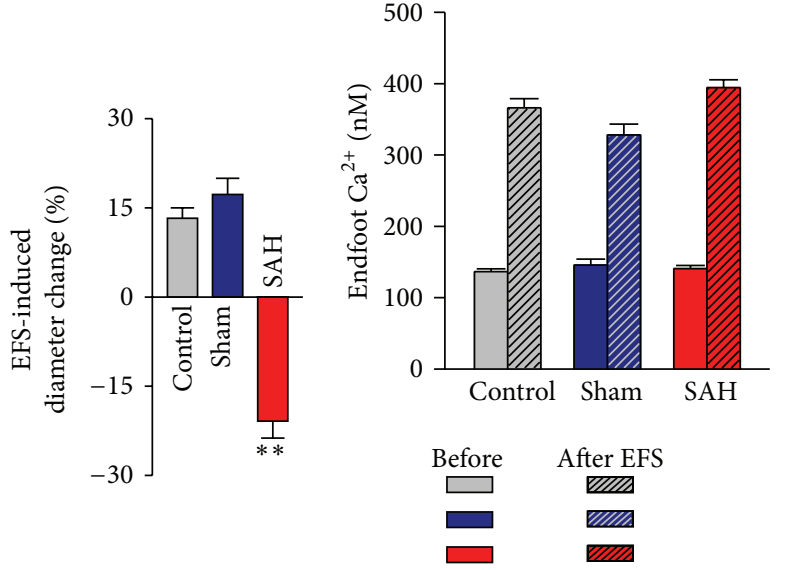

(b)

(c)

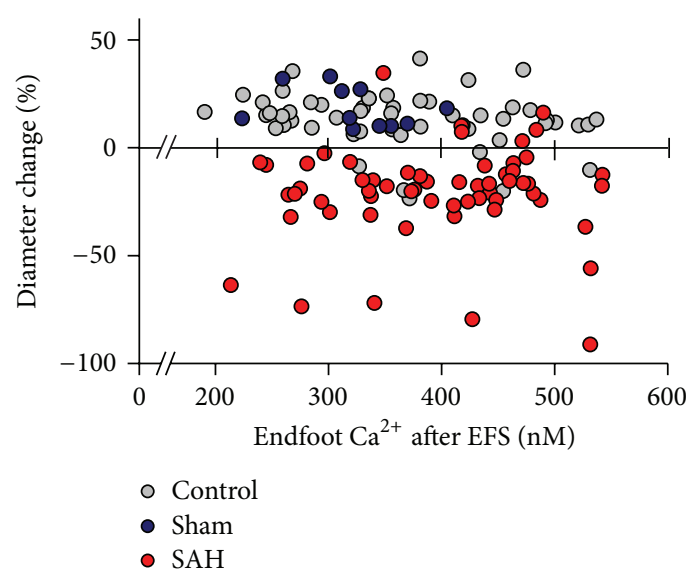

(d)

FIGURE 1: Inversion of neurovascular coupling in cortical brain slices from SAH model animals. (a) (Upper) Infrared-differential interference contrast images from brain slices of control, sham-operated, and SAH model rats before/after electrical field stimulation (EFS). Parenchymal arterioles were preconstricted with U46619 $(100 \mathrm{nM})$. Dashed lines in red display the intraluminal diameter of parenchymal arterioles. Overlapping pseudocolor-mapped $\mathrm{Ca}^{2+}$ levels in astrocyte endfeet were obtained by simultaneous imaging using the fluorescent $\mathrm{Ca}^{2+}$ indicator fluo-4 and two-photon microscopy. Scale bar: $10 \mu \mathrm{m}$. (Lower) Simultaneous recordings of EFS-induced changes in diameter and estimated endfoot $\mathrm{Ca}^{2+}$ concentrations obtained from brain slices depicted in upper images. (b)-(d) Summary data of EFS-evoked changes in arteriolar diameter and astrocytic endfoot $\mathrm{Ca}^{2+}$ obtained from control $(n=53)$, sham-operated $(n=11)$, and SAH model $(n=59)$ animals. Diameter changes were expressed as percentage of the diameter in the same point before EFS as $100 \%$. ${ }^{* *} P<0.01$ by one-way ANOVA followed by host hoc comparison of means using the Tukey test (modified from Koide et al. [21]).

Further, delayed blood-induced vasospasm of brain surface conduit arteries [103] and enhanced constriction of resistance-size cerebral arteries and arterioles [18, 104, 105] may also reduce blood flow to ischemic levels, contributing to the development of delayed ischemic neuronal deficits. Data presented above indicate that both SAH and global ischemia can lead to decreased neurovascular coupling. However, a marked difference regarding the influence of SAH and global ischemia on neurovascular coupling is apparent; SAH causes inversion of the neurovascular response from vasodilation to vasoconstriction whereas global ischemia causes a decrease in the magnitude of the dilation to evoked neuronal activity.

\section{Conclusions}

Subarachnoid hemorrhage is a multifaceted pathology exhibiting both acute and long-term injury to the brain. It is now clear that SAH profoundly impacts neuronal influences on the vasculature leading to decreased cerebral blood flow that can exacerbate the extent of brain damage. One type of SAH-induced impaired neurovascular signaling arises in the context of SD that can impact large areas of cortical and subcortical grey matter. In the absence of SAH, SD is most frequently associated with a hyperemic response, that is, an increase in cerebral blood flow. However, SAH causes an 


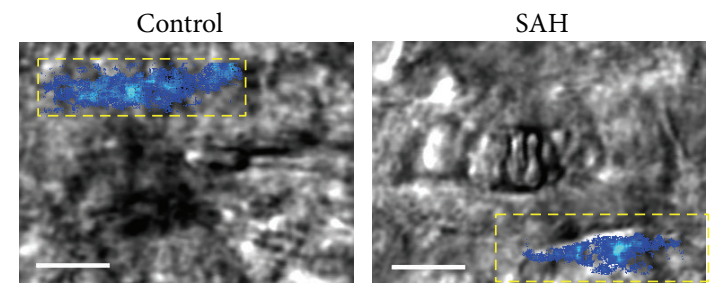

(a)
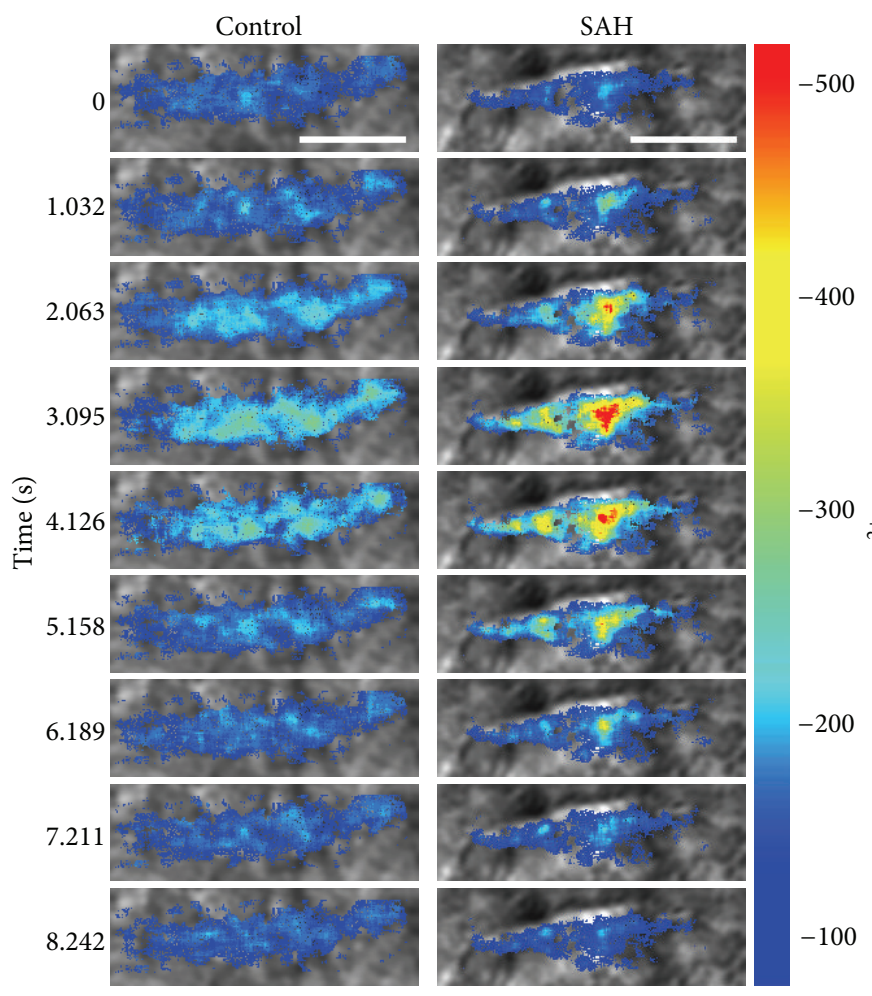
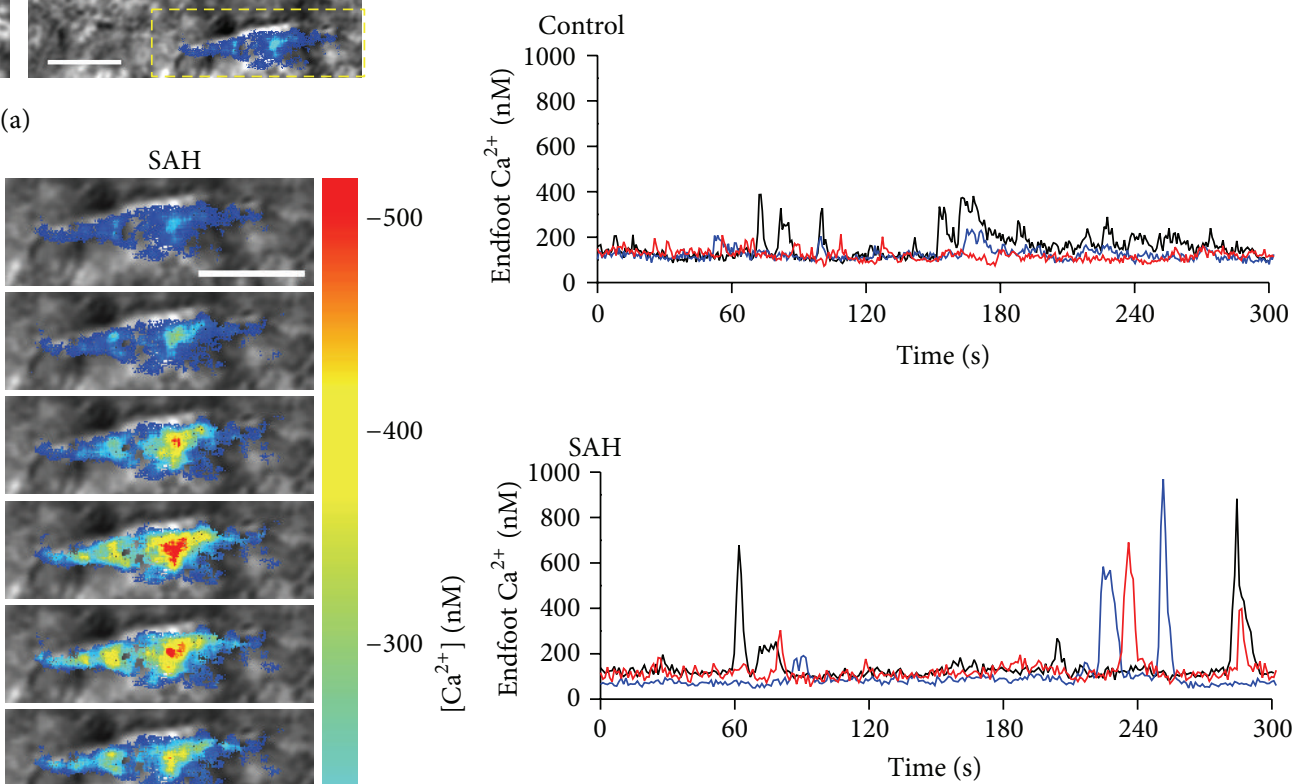

(c)

(b)

FIGURE 2: Increased amplitude of spontaneous $\mathrm{Ca}^{2+}$ oscillations in astrocyte endfeet following SAH. (a)-(b) Representative images of spontaneous $\mathrm{Ca}^{2+}$ oscillation in astrocyte endfeet in brain slices from control and SAH model animals. (b) Time laps images from the area within the yellow dotted box in Figure 2(a). Scale bar: $10 \mu \mathrm{m}$. (c) Spontaneous $\mathrm{Ca}^{2+}$ oscillations in a brain slice from control (upper) and SAH model (lower) animals. Traces were obtained from $1.2 \times 1.2-\mu \mathrm{m}$ regions of interest placed on distinct astrocyte endfeet in $5 \mathrm{~min}$ recordings without stimulation (modified from Koide et al. [21]).

inversion of the SD-induced neurovascular response leading to vasoconstriction and decreased blood flow to tissue during a time of high metabolic demand. Recently, it has also been shown that SAH can cause inversion of neurovascular coupling at the level of the individual neurovascular unit. Physiologically, coordinated activity of neurons, astrocytes, and parenchymal arterioles ensures increase local blood flow to active neurons in specific regions of the brain engaged in task-dependent processes. After SAH the neurovascular response to neuronal activation switches from vasodilation to vasoconstriction; this also promotes a pathological decrease in the flow of oxygen and nutrients to metabolically active neurons. Evidence suggests that elevated perivascular $\mathrm{K}^{+}$due to the enhanced amplitude of spontaneous $\mathrm{Ca}^{2+}$ signaling events in astrocytic endfeet may underlie this inversion of neurovascular coupling, consistent with a bimodal effect of extracellular $\mathrm{K}^{+}$to cause vasodilation at concentrations below $20 \mathrm{mM}$ and constriction when this threshold of $20 \mathrm{mM}$ is exceeded. Presently mechanisms associated with inversion of the neurovascular response caused by SAH-induced SD have not completely been resolved. However, inversion of SDinduced neurovascular response likely reflects a combination of increased extracellular $\mathrm{K}^{+}$and the impact of SAH on the relative balance of vasoconstrictor and vasodilator influences. Development of agents and approaches to prevent SAHinduced inversion of neurovascular coupling may provide a much needed additional therapeutic option for SAH patients.

\section{Acknowledgments}

This work was supported by the National Institutes of Health (P01-HL095488, R01-HL078983, R01-HL078983-05S1 (GCW) 

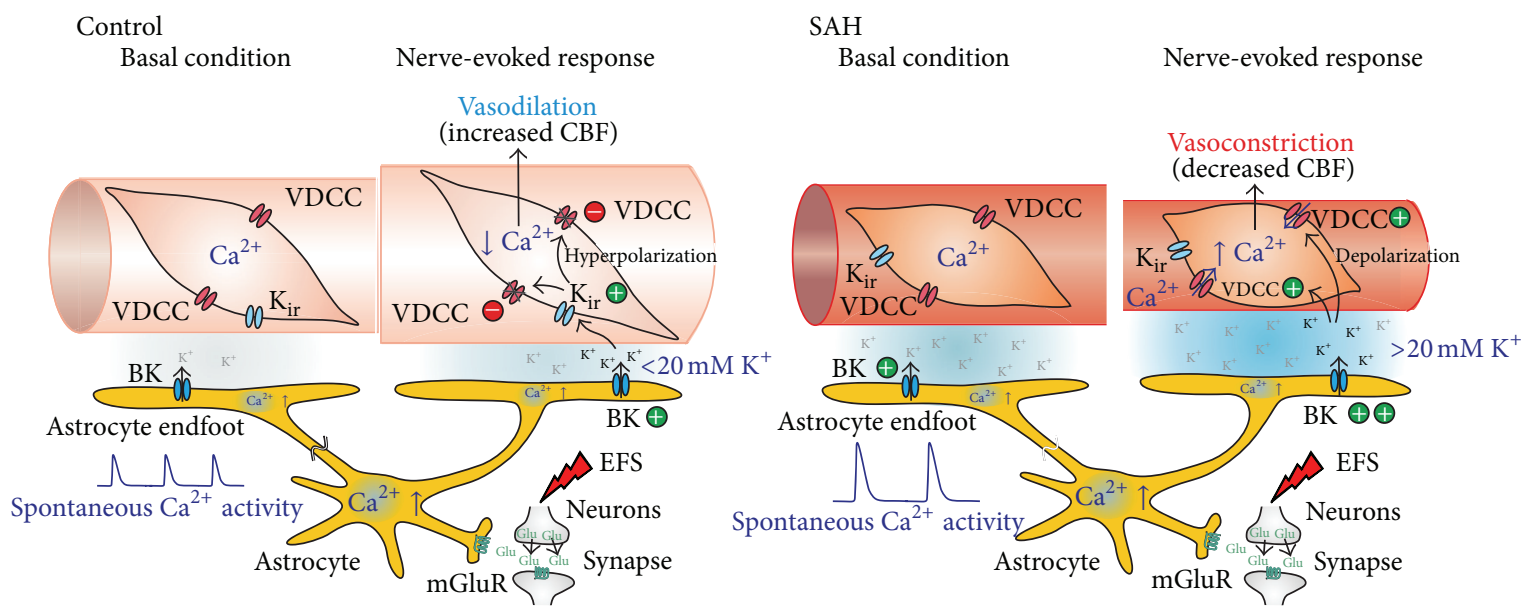

FIGURE 3: Schematic model liking SAH to inversion of neurovascular coupling. In control animals, EFS causes elevated cytoplasmic Ca ${ }^{2+}$ in astrocytes leading to increased BK channel activity and modest $(<20 \mathrm{mM})$ increases in perivascular $\mathrm{K}^{+}$, promoting vasodilation. SAH increases the magnitude of spontaneous astrocytic $\mathrm{Ca}^{2+}$ oscillations and basal activity of BK channels, elevating $\mathrm{K}^{+}$in restricted perivascular space. The summation of increased basal perivascular $\mathrm{K}^{+}$and "normal" nerve-evoked astrocyte BK channel activity results in extracellular $\mathrm{K}^{+}$ concentrations that exceed the dilation-constriction threshold $(\sim 20 \mathrm{mM})$, inducing vasoconstriction. BK: large conductance Ca ${ }^{2+}$-activated $\mathrm{K}^{+}$channel, CBF: cerebral blood flow, EFS: electrical field stimulation, Glu: glutamate, $\mathrm{K}_{\mathrm{ir}}$ : inward rectifier $\mathrm{K}^{+}$channel, mGluR: metabotropic glutamate receptor, VDCC: voltage-dependent $\mathrm{Ca}^{2+}$ channel (modified from Koide et al. [21]).

and NS061505 (CA)), The Heitman Foundation (CA), The Ellison Foundation (CA), The Totman Medical Research Trust (GCW), and the Peter Martin Aneurysm Endowment (GCW).

\section{References}

[1] J. B. Bederson, E. S. Connolly Jr., H. H. Batjer et al., "Guidelines for the management of aneurysmal subarachnoid hemorrhage: a statement for healthcare professionals from a special writing group of the Stroke Council, American Heart Association," Stroke, vol. 40, no. 3, pp. 994-1025, 2009.

[2] M. D. Vergouwen, M. Vermeulen, J. van Gijn et al., "Definition of delayed cerebral ischemia after aneurysmal subarachnoid hemorrhage as an outcome event in clinical trials and observational studies: proposal of a multidisciplinary research group," Stroke, vol. 41, no. 10, pp. 2391-2395, 2010.

[3] H. H. Dietrich and R. G. Dacey Jr., "Molecular keys to the problems of cerebral vasospasm," Neurosurgery, vol. 46, no. 3, pp. 517-530, 2000.

[4] N. F. Kassell, T. Sasaki, A. R. T. Colohan, and G. Nazar, "Cerebral vasospasm following aneurysmal subarachnoid hemorrhage," Stroke, vol. 16, no. 4, pp. 562-572, 1985.

[5] J. Hansen-Schwartz, P. Vajkoczy, R. L. Macdonald, R. M. Pluta, and J. H. Zhang, "Cerebral vasospasm: looking beyond vasoconstriction," Trends in Pharmacological Sciences, vol. 28, no. 6, pp. 252-256, 2007.

[6] J. H. Zhang, R. M. Pluta, J. Hansen-Schwartz et al., "Cerebral vasospasm following subarachnoid hemorrhage: time for a new world of thought," Neurological Research, vol. 31, no. 2, pp. 151158, 2009.

[7] A. A. Rabinstein, S. Weigand, J. L. D. Atkinson, and E. F. M. Wijdicks, "Patterns of cerebral infarction in aneurysmal subarachnoid hemorrhage," Stroke, vol. 36, no. 5, pp. 992-997, 2005.
[8] R. P. Ostrowski, A. R. Colohan, and J. H. Zhang, "Molecular mechanisms of early brain injury after subarachnoid hemorrhage," Neurological Research, vol. 28, no. 4, pp. 399-414, 2006.

[9] G. F. Prunell, N. A. Svendgaard, K. Alkass, and T. Mathiesen, "Delayed cell death related to acute cerebral blood flow changes following subarachnoid hemorrhage in the rat brain," Journal of Neurosurgery, vol. 102, no. 6, pp. 1046-1054, 2005.

[10] F. A. Sehba, J. Hou, R. M. Pluta, and J. H. Zhang, "The importance of early brain injury after subarachnoid hemorrhage," Progress in Neurobiology, vol. 97, no. 1, pp. 14-37, 2012.

[11] O. Altay, H. Suzuki, Y. Hasegawa et al., "Isoflurane attenuates blood-brain barrier disruption in ipsilateral hemisphere after subarachnoid hemorrhage in mice," Stroke, vol. 43, no. 9, pp. 2513-2516, 2012.

[12] T. Doczi, "The pathogenetic and prognostic significance of blood-brain barrier damage at the acute stage of aneurysmal subarachnoid haemorrhage. Clinical and experimental studies," Acta Neurochirurgica, vol. 77, no. 3-4, pp. 110-132, 1985.

[13] K. Fassbender, B. Hodapp, S. Rossol et al., "Inflammatory cytokines in subarachnoid haemorrhage: association with abnormal blood flow velocities in basal cerebral arteries," Journal of Neurology Neurosurgery and Psychiatry, vol. 70, no. 4, pp. 534-537, 2001.

[14] K. Murakami, M. Koide, T. M. Dumont, S. R. Russell, B. I. Tranmer, and G. C. Wellman, "Subarachnoid hemorrhage induces gliosis and increased expression of the pro-inflammatory cytokine high mobility group box 1 protein," Translational Stroke Research, vol. 2, no. 1, pp. 72-79, 2011.

[15] J. Marc Simard, Z. Geng, S. Kyoon Woo et al., "Glibenclamide reduces inflammation, vasogenic edema, and caspase-3 activation after subarachnoid hemorrhage," Journal of Cerebral Blood Flow and Metabolism, vol. 29, no. 2, pp. 317-330, 2009.

[16] M. Ishiguro, C. B. Puryear, E. Bisson et al., "Enhanced myogenic tone in cerebral arteries from a rabbit model of subarachnoid hemorrhage," American Journal of Physiology, Heart and Circulatory Physiology, vol. 283, no. 6, pp. H2217-H2225, 2002. 
[17] M. Koide, M. A. Nystoriak, G. Krishnamoorthy et al., "Reduced $\mathrm{Ca}^{2+}$ spark activity after subarachnoid hemorrhage disables BK channel control of cerebral artery tone," Journal of Cerebral Blood Flow and Metabolism, vol. 31, no. 1, pp. 3-16, 2011.

[18] M. A. Nystoriak, K. P. O’Connor, S. K. Sonkusare, J. E. Brayden, M. T. Nelson, and G. C. Wellman, "Fundamental increase in pressure-dependent constriction of brain parenchymal arterioles from subarachnoid hemorrhage model rats due to membrane depolarization," American Journal of Physiology, Heart and Circulatory Physiology, vol. 300, no. 3, pp. H803-H812, 2011.

[19] M. D. I. Vergouwen, M. Vermeulen, B. A. Coert, E. S. G. Stroes, and Y. B. W. E. M. Roos, "Microthrombosis after aneurysmal subarachnoid hemorrhage: an additional explanation for delayed cerebral ischemia," Journal of Cerebral Blood Flow and Metabolism, vol. 28, no. 11, pp. 1761-1770, 2008.

[20] J. P. Dreier, S. Major, A. Manning et al., "Cortical spreading ischaemia is a novel process involved in ischaemic damage in patients with aneurysmal subarachnoid haemorrhage," Brain, vol. 132, no. 7, pp. 1866-1881, 2009.

[21] M. Koide, A. D. Bonev, M. T. Nelson, and G. C. Wellman, "Inversion of neurovascular coupling by subarachnoid blood depends on large-conductance $\mathrm{Ca}^{2+}$-activated $\mathrm{K}^{+}$(BK) channels," Proceedings of the National Academy of Sciences of the United States of America, vol. 109, no. 21, pp. E1387-E1395, 2012.

[22] A. A. Leao, "Spreading depression of activity in the cerebral cortex," Journal of Neurophysiology, vol. 7, pp. 359-390, 1944.

[23] C. Ayata, "Cortical spreading depression triggers migraine attack: pro," Headache, vol. 50, no. 4, pp. 725-730, 2010.

[24] M. Lauritzen, J. P. Dreier, M. Fabricius, J. A. Hartings, R. Graf, and A. J. Strong, "Clinical relevance of cortical spreading depression in neurological disorders: migraine, malignant stroke, subarachnoid and intracranial hemorrhage, and traumatic brain injury," Journal of Cerebral Blood Flow and Metabolism, vol. 31, no. 1, pp. 17-35, 2011.

[25] J. C. Chang, L. L. Shook, J. Biag et al., "Biphasic direct current shift, haemoglobin desaturation and neurovascular uncoupling in cortical spreading depression," Brain, vol. 133, no. 4, pp. 9961012, 2010.

[26] M. Guiou, S. Sheth, M. Nemoto et al., "Cortical spreading depression produces long-term disruption of activity-related changes in cerebral blood volume and neurovascular coupling," Journal of Biomedical Optics, vol. 10, no. 1, article 11004, 2005.

[27] H. Piilgaard and M. Lauritzen, "Persistent increase in oxygen consumption and impaired neurovascular coupling after spreading depression in rat neocortex," Journal of Cerebral Blood Flow and Metabolism, vol. 29, no. 9, pp. 1517-1527, 2009.

[28] H. Piilgaard, B. M. Witgen, P. Rasmussen, and M. Lauritzen, "Cyclosporine A, FK506, and NIM811 ameliorate prolonged $\mathrm{CBF}$ reduction and impaired neurovascular coupling after cortical spreading depression," Journal of Cerebral Blood Flow and Metabolism, vol. 31, no. 7, pp. 1588-1598, 2011.

[29] J. P. Dreier, J. Woitzik, M. Fabricius et al., "Delayed ischaemic neurological deficits after subarachnoid haemorrhage are associated with clusters of spreading depolarizations," Brain, vol. 129, no. 12, pp. 3224-3237, 2006.

[30] J. P. Dreier, "The role of spreading depression, spreading depolarization and spreading ischemia in neurological disease," Nature Medicine, vol. 17, no. 4, pp. 439-447, 2011.

[31] J. A. Hartings, M. R. Bullock, D. O. Okonkwo et al., "Spreading depolarisations and outcome after traumatic brain injury: a prospective observational study," Lancet Neurology, vol. 10, no. 12, pp. 1058-1064, 2011.
[32] O. W. Sakowitz, E. Santos, A. Nagel et al., "Clusters of spreading depolarizations are associated with disturbed cerebral metabolism in patients with aneurysmal subarachnoid hemorrhage," Stroke, vol. 44, no. 1, pp. 220-223, 2013.

[33] H. K. Shin, A. K. Dunn, P. B. Jones, D. A. Boas, M. A. Moskowitz, and C. Ayata, "Vasoconstrictive neurovascular coupling during focal ischemic depolarizations," Journal of Cerebral Blood Flow and Metabolism, vol. 26, no. 8, pp. 1018-1030, 2006.

[34] J. P. Dreier, K. Körner, N. Ebert et al., "Nitric oxide scavenging by hemoglobin or nitric oxide synthase inhibition by $\mathrm{N}$-nitroL-arginine induces cortical spreading ischemia when $\mathrm{K}^{+}$is increased in the subarachnoid space," Journal of Cerebral Blood Flow and Metabolism, vol. 18, no. 9, pp. 978-990, 1998.

[35] G. C. Petzold, S. Haack, O. Von Bohlen Und Halbach et al., "Nitric oxide modulates spreading depolarization threshold in the human and rodent cortex," Stroke, vol. 39, no. 4, pp. 12921299, 2008.

[36] J. P. Dreier, N. Ebert, J. Priller et al., "Products of hemolysis in the subarachnoid space inducing spreading ischemia in the cortex and focal necrosis in rats: a model for delayed ischemic neurological deficits after subarachnoid hemorrhage?" Journal of Neurosurgery, vol. 93, no. 4, pp. 658-666, 2000.

[37] G. C. Petzold, K. M. Einhäupl, U. Dirnagl, and J. P. Dreier, "Ischemia triggered by spreading neuronal activation is induced by endothelin-1 and hemoglobin in the subarachnoid space," Annals of Neurology, vol. 54, no. 5, pp. 591-598, 2003.

[38] D. Jorks, S. Major, A. I. Oliveira-Ferreira, J. Kleeberg, and J. P. Dreier, "Endothelin-1(1-31) induces spreading depolarization in rats," Acta Neurochirurgica, vol. 110, no. 1, pp. 111-117, 2011.

[39] J. Kleeberg, G. C. Petzold, S. Major, U. Dirnagl, and J. P. Dreier, "ET-1 induces cortical spreading depression via activation of the ET A receptor/phospholipase C pathway in vivo," American Journal of Physiology, Heart and Circulatory Physiology, vol. 286, no. 4, pp. H1339-H1346, 2004.

[40] A. I. Oliveira-Ferreira, D. Milakara, M. Alam et al., "Experimental and preliminary clinical evidence of an ischemic zone with prolonged negative DC shifts surrounded by a normally perfused tissue belt with persistent electrocorticographic depression," Journal of Cerebral Blood Flow and Metabolism, vol. 30, no. 8, pp. 1504-1519, 2010.

[41] C. Ayata, H. K. Shin, S. Salomone et al., "Pronounced hypoperfusion during spreading depression in mouse cortex," Journal of Cerebral Blood Flow and Metabolism, vol. 24, no. 10, pp. 1172$1182,2004$.

[42] E. Farkas, R. Pratt, F. Sengpiel, and T. P. Obrenovitch, "Direct, live imaging of cortical spreading depression and anoxic depolarisation using a fluorescent, voltage-sensitive dye," Journal of Cerebral Blood Flow and Metabolism, vol. 28, no. 2, pp. 251-262, 2008.

[43] M. Lauritzen, "Cerebral blood flow in migraine and cortical spreading depression," Acta Neurologica Scandinavica, vol. 113, pp. 1-40, 1987.

[44] M. Lauritzen, "Regional cerebral blood flow during cortical spreading depression in rat brain: increased reactive hyperperfusion in low-flow states," Acta Neurologica Scandinavica, vol. 75, no. 1, pp. 1-8, 1987.

[45] R. D. Piper, G. A. Lambert, and J. W. Duckworth, "Cortical blood flow changes during spreading depression in cats," American Journal of Physiology, Heart and Circulatory Physiology, vol. 261, no. 1, pp. H96-H102, 1991.

[46] J. Sonn and A. Mayevsky, "Effects of brain oxygenation on metabolic, hemodynamic, ionic and electrical responses to 
spreading depression in the rat," Brain Research, vol. 882, no. 1-2, pp. 212-216, 2000.

[47] M. Shinohara, B. Dollinger, and G. Brown, "Cerebral glucose utilization: local changes during and after recovery from spreading cortical depression," Science, vol. 203, no. 4376, pp. 188-190, 1979.

[48] R. B. Duckrow, "A brief hypoperfusion precedes spreading depression if nitric oxide synthesis is inhibited," Brain Research, vol. 618, no. 2, pp. 190-195, 1993.

[49] M. Lauritzen and M. Fabricius, "Peal time laser-Doppler perfusion imaging of cortical spreading depression in rat neocortex," NeuroReport, vol. 6, no. 9, pp. 1271-1273, 1995.

[50] T. Osada, M. Tomita, and N. Suzuki, "Spindle-shaped constriction and propagated dilation of arterioles during cortical spreading depression," NeuroReport, vol. 17, no. 12, pp. 1365$1368,2006$.

[51] Y. Tomita, M. Tomita, I. Schiszler et al., "Repetitive concentric wave-ring spread of oligemia/hyperemia in the sensorimotor cortex accompanying $\mathrm{K}^{+}$-induced spreading depression in rats and cats," Neuroscience Letters, vol. 322, no. 3, pp. 157-160, 2002.

[52] J. Chuquet, L. Hollender, and E. A. Nimchinsky, "Highresolution in vivo imaging of the neurovascular unit during spreading depression," Journal of Neuroscience, vol. 27, no. 15, pp. 4036-4044, 2007.

[53] U. Hoffmann and C. Ayata, "Neurovascular coupling during spreading depolarizations," Acta Neurochirurgica, vol. 115, pp. 161-165, 2013.

[54] J. P. Dreier, O. Windmüller, G. Petzold et al., "Ischemia triggered by red blood cell products in the subarachnoid space is inhibited by nimodipine administration or moderate volume expansion/hemodilution in rats," Neurosurgery, vol. 51, no. 6, pp. 1457-1467, 2002.

[55] I. Sukhotinsky, M. A. Yaseen, S. Sakadžić et al., "Perfusion pressure-dependent recovery of cortical spreading depression is independent of tissue oxygenation over a wide physiologic range," Journal of Cerebral Blood Flow and Metabolism, vol. 30, no. 6, pp. 1168-1177, 2010.

[56] A. J. Strong, P. J. Anderson, H. R. Watts et al., "Peri-infarct depolarizations lead to loss of perfusion in ischaemic gyrencephalic cerebral cortex," Brain, vol. 130, no. 4, pp. 995-1008, 2007.

[57] J. Woitzik, J. P. Dreier, N. Hecht et al., "Delayed cerebral ischemia and spreading depolarization in absence of angiographic vasospasm after subarachnoid hemorrhage," Journal of Cerebral Blood Flow and Metabolism, vol. 32, no. 2, pp. 203-212, 2012.

[58] T. Kumagai, M. Walberer, H. Nakamura et al., "Distinct spatiotemporal patterns of spreading depolarizations during early infarct evolution: evidence from real-time imaging," Journal of Cerebral Blood Flow and Metabolism, vol. 31, no. 2, pp. 580-592, 2011.

[59] J. Luckl, C. Zhou, T. Durduran, A. G. Yodh, and J. H. Greenberg, "Characterization of periinfarct flow transients with laser speckle and Doppler after middle cerebral artery occlusion in the rat," Journal of Neuroscience Research, vol. 87, no. 5, pp. 12191229, 2009.

[60] H. Nakamura, A. J. Strong, C. Dohmen et al., "Spreading depolarizations cycle around and enlarge focal ischaemic brain lesions," Brain, vol. 133, no. 7, pp. 1994-2006, 2010.

[61] I. Sukhotinsky, E. Dilekoz, M. A. Moskowitz, and C. Ayata, "Hypoxia and hypotension transform the blood flow response to cortical spreading depression from hyperemia into hypoperfusion in the rat," Journal of Cerebral Blood Flow and Metabolism, vol. 28, no. 7, pp. 1369-1376, 2008.

[62] U. Hoffmann, I. Sukhotinsky, Y. B. Atalay, K. EikermannHaerter, and C. Ayata, "Increased glucose availability does not restore prolonged spreading depression durations in hypotensive rats without brain injury," Experimental Neurology, vol. 238, no. 2, pp. 130-132, 2012.

[63] M. Fabricius, S. Fuhr, R. Bhatia et al., "Cortical spreading depression and peri-infarct depolarization in acutely injured human cerebral cortex," Brain, vol. 129, no. 3, pp. 778-790, 2006.

[64] G. C. Petzold, O. Windmüller, S. Haack et al., "Increased extracellular $\mathrm{K}^{+}$concentration reduces the efficacy of N-methyl-Daspartate receptor antagonists to block spreading depressionlike depolarizations and spreading ischemia," Stroke, vol. 36, no. 6, pp. 1270-1277, 2005.

[65] J. P. Dreier, G. Petzold, K. Tille et al., "Ischaemia triggered by spreading neuronal activation is inhibited by vasodilators in rats," Journal of Physiology, vol. 531, no. 2, pp. 515-526, 2001.

[66] G. B. Pike, "Quantitative functional MRI: concepts, issues and future challenges," Neuroimage, vol. 62, no. 2, pp. 1234-1240, 2012.

[67] C. Iadecola and M. Nedergaard, "Glial regulation of the cerebral microvasculature," Nature Neuroscience, vol. 10, no. 11, pp. 13691376, 2007.

[68] D. Attwell, A. M. Buchan, S. Charpak, M. Lauritzen, B. A. MacVicar, and E. A. Newman, "Glial and neuronal control of brain blood flow," Nature, vol. 468, no. 7321, pp. 232-243, 2010.

[69] K. M. Dunn and M. T. Nelson, "Potassium channels and neurovascular coupling," Circulation Journal, vol. 74, no. 4, pp. 608-616, 2010.

[70] C. Iadecola, "Neurovascular regulation in the normal brain and in Alzheimer's disease," Nature Reviews Neuroscience, vol. 5, no. 5, pp. 347-360, 2004.

[71] C. M. Anderson and M. Nedergaard, "Astrocyte-mediated control of cerebral microcirculation," Trends in Neurosciences, vol. 26, no. 7, pp. 340-344, 2003.

[72] J. A. Filosa, A. D. Bonev, and M. T. Nelson, "Calcium dynamics in cortical astrocytes and arterioles during neurovascular coupling," Circulation Research, vol. 95, no. 10, pp. e73-e81, 2004.

[73] M. Simard, G. Arcuino, T. Takano, Q. S. Liu, and M. Nedergaard, "Signaling at the gliovascular interface," Journal of Neuroscience, vol. 23, no. 27, pp. 9254-9262, 2003.

[74] S. V. Straub, A. D. Bonev, M. K. Wilkerson, and M. T. Nelson, "Dynamic inositol trisphosphate-mediated calcium signals within astrocytic endfeet underlie vasodilation of cerebral arterioles," Journal of General Physiology, vol. 128, no. 6, pp. 659669, 2006.

[75] S. V. Straub and M. T. Nelson, "Astrocytic calcium signaling: the information currency coupling neuronal activity to the cerebral microcirculation," Trends in Cardiovascular Medicine, vol. 17, no. 6, pp. 183-190, 2007.

[76] B. Cauli and E. Hamel, "Revisiting the role of neurons in neurovascular coupling," Frontiers in Neuroenergetics, vol. 2, article 9, 2010.

[77] E. Hamel, "Perivascular nerves and the regulation of cerebrovascular tone," Journal of Applied Physiology, vol. 100, no. 3, pp. 1059-1064, 2006.

[78] C. Lecrux, X. Toussay, A. Kocharyan et al., "Pyramidal neurons are "neurogenic hubs" in the neurovascular coupling response to whisker stimulation," Journal of Neuroscience, vol. 31, no. 27, pp. 9836-9847, 2011. 
[79] P. G. Haydon and G. Carmignoto, "Astrocyte control of synaptic transmission and neurovascular coupling," Physiological Reviews, vol. 86, no. 3, pp. 1009-1031, 2006.

[80] R. C. Koehler, R. J. Roman, and D. R. Harder, "Astrocytes and the regulation of cerebral blood flow," Trends in Neurosciences, vol. 32, no. 3, pp. 160-169, 2009.

[81] M. Zonta, M. C. Angulo, S. Gobbo et al., "Neuron-to-astrocyte signaling is central to the dynamic control of brain microcirculation," Nature Neuroscience, vol. 6, no. 1, pp. 43-50, 2003.

[82] D. L. Price, J. W. Ludwig, H. Mi, T. L. Schwarz, and M. H. Ellisman, "Distribution of rSlo $\mathrm{Ca}^{2+}$-activated $\mathrm{K}^{+}$channels in rat astrocyte perivascular endfeet," Brain Research, vol. 956, no. 2, pp. 183-193, 2002.

[83] J. A. Filosa, A. D. Bonev, S. V. Straub et al., "Local potassium signaling couples neuronal activity to vasodilation in the brain," Nature Neuroscience, vol. 9, no. 11, pp. 1397-1403, 2006.

[84] H. Girouard, A. D. Bonev, R. M. Hannah, A. Meredith, R. W. Aldrich, and M. T. Nelson, "Astrocytic endfoot $\mathrm{Ca}^{2+}$ and BK channels determine both arteriolar dilation and constriction," Proceedings of the National Academy of Sciences of the United States of America, vol. 107, no. 8, pp. 3811-3816, 2010.

[85] O. B. Paulson and E. A. Newman, "Does the release of potassium from astrocyte endfeet regulate cerebral blood flow?" Science, vol. 237, no. 4817, pp. 896-898, 1987.

[86] G. R. J. Gordon, H. B. Choi, R. L. Rungta, G. C. R. Ellis-Davies, and B. A. MacVicar, "Brain metabolism dictates the polarity of astrocyte control over arterioles," Nature, vol. 456, no. 7223, pp. 745-750, 2008.

[87] M. R. Metea and E. A. Newman, "Glial cells dilate and constrict blood vessels: a mechanism of neurovascular coupling," Journal of Neuroscience, vol. 26, no. 11, pp. 2862-2870, 2006.

[88] S. J. Mulligan and B. A. MacVicar, "Calcium transients in astrocyte endfeet cause cerebrovascular constrictions," Nature, vol. 431, no. 7005, pp. 195-199, 2004.

[89] J. J. Zaritsky, D. M. Eckman, G. C. Wellman, M. T. Nelson, and T. L. Schwarz, "Targeted disruption of Kir2.1 and Kir2.2 genes reveals the essential role of the inwardly rectifying $\mathrm{K}^{+}$current in $\mathrm{K}^{+}$-mediated vasodilation," Circulation Research, vol. 87, no. 2, pp. 160-166, 2000.

[90] H. R. Parri, T. M. Gould, and V. Crunelli, "Spontaneous astrocytic $\mathrm{Ca}^{2+}$ oscillations in situ drive NMDAR-mediated neuronal excitation," Nature Neuroscience, vol. 4, no. 8, pp. 803812, 2001.

[91] W. J. Nett, S. H. Oloff, and K. D. Mccarthy, "Hippocampal astrocytes in situ exhibit calcium oscillations that occur independent of neuronal activity," Journal of Neurophysiology, vol. 87, no. 1, pp. 528-537, 2002.

[92] F. Aguado, J. F. Espinosa-Parrilla, M. A. Carmona, and E. Soriano, "Neuronal activity regulates correlated network properties of spontaneous calcium transients in astrocytes in situ," Journal of Neuroscience, vol. 22, no. 21, pp. 9430-9444, 2002.

[93] H. Hirase, L. Qian, P. Barthó, and G. Buzsáki, "Calcium dynamics of cortical astrocytic networks in vivo," PLoS Biology, vol. 2, no. 4, article E96, 2004.

[94] T. Takano, X. Han, R. Deane, B. Zlokovic, and M. Nedergaard, "Two-photon imaging of astrocytic $\mathrm{Ca}^{2+}$ signaling and the microvasculature in experimental mice models of Alzheimer's disease," Annals of the New York Academy of Sciences, vol. 1097, pp. 40-50, 2007.

[95] I. Harukuni and A. Bhardwaj, "Mechanisms of brain injury after global cerebral ischemia," Neurologic Clinics, vol. 24, no. 1, pp. 121, 2006.
[96] C. Zhou, T. Shimazu, T. Durduran et al., "Acute functional recovery of cerebral blood flow after forebrain ischemia in rat," Journal of Cerebral Blood Flow and Metabolism, vol. 28, no. 7, pp. 1275-1284, 2008.

[97] W. B. Baker, Z. Sun, T. Hiraki et al., "Neurovascular coupling varies with level of global cerebral ischemia in a rat model," Journal of Cerebral Blood Flow and Metabolism, vol. 33, no. 1, pp. 97-105, 2013.

[98] W. D. Dietrich, M. D. Ginsberg, and R. Busto, "Effect of transient cerebral ischemia on metabolic activation of a somatosensory circuit," Journal of Cerebral Blood Flow and Metabolism, vol. 6, no. 4, pp. 405-413, 1986.

[99] M. J. Cipolla, N. Lessov, E. S. Hammer, and A. B. Curry, "Threshold duration of ischemia for myogenic tone in middle cerebral arteries: effect on vascular smooth muscle actin," Stroke, vol. 32, no. 7, pp. 1658-1664, 2001.

[100] H. Girouard and C. Iadecola, "Neurovascular coupling in the normal brain and in hypertension, stroke, and Alzheimer disease," Journal of Applied Physiology, vol. 100, no. 1, pp. 328335, 2006.

[101] O. Butenko, D. Dzamba, J. Benesova et al., "The increased activity of TRPV4 channel in the astrocytes of the adult rat hippocampus after cerebral hypoxia/ischemia," PLoS ONE, vol. 7, no. 6, Article ID e39959, 2012.

[102] H. Pivonkova, J. Benesova, O. Butenko, A. Chvatal, and M. Anderova, "Impact of global cerebral ischemia on $\mathrm{K}^{+}$channel expression and membrane properties of glial cells in the rat hippocampus," Neurochemistry International, vol. 57, no. 7, pp. 783-794, 2010.

[103] S. Nishizawa and I. Laher, "Signaling mechanisms in cerebral vasospasm," Trends in Cardiovascular Medicine, vol. 15, no. 1, pp. 24-34, 2005.

[104] M. Ishiguro, T. L. Wellman, A. Honda, S. R. Russell, B. I. Tranmer, and G. C. Wellman, "Emergence of a R-type Ca ${ }^{2+}$ channel (Cav 2.3) contributes to cerebral artery constriction after subarachnoid hemorrhage," Circulation Research, vol. 96, no. 4, pp. 419-426, 2005.

[105] G. C. Wellman, "Ion channels and calcium signaling in cerebral arteries following subarachnoid hemorrhage," Neurological Research, vol. 28, no. 7, pp. 690-702, 2006. 


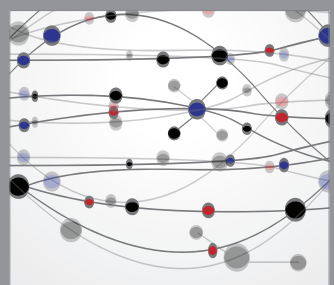

The Scientific World Journal
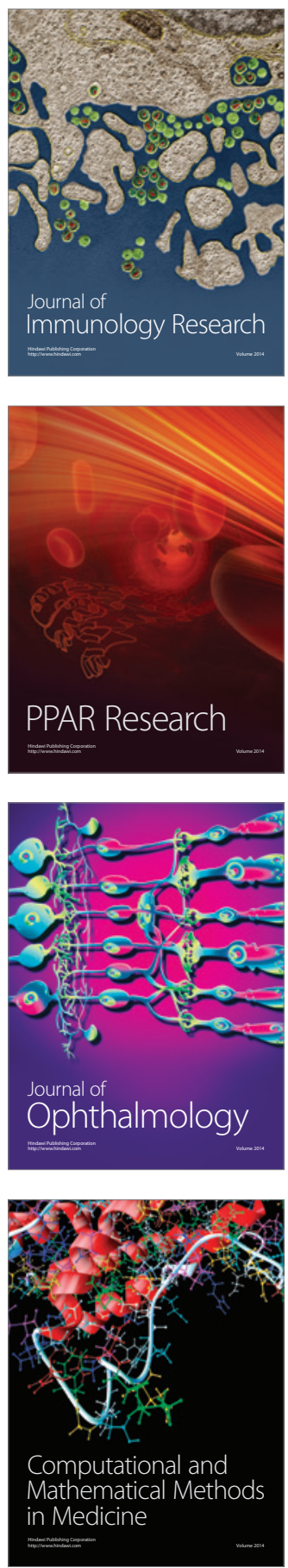

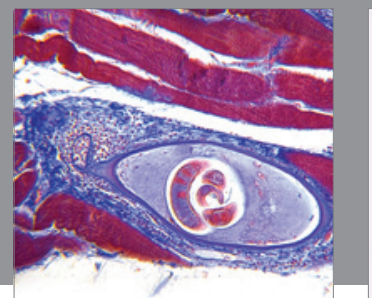

Gastroenterology

Research and Practice
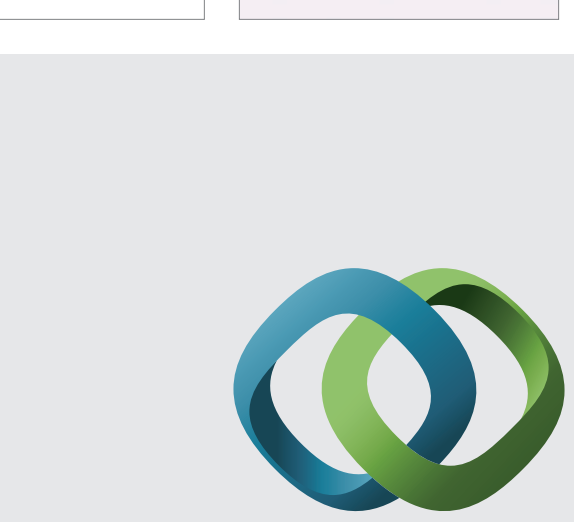

\section{Hindawi}

Submit your manuscripts at

http://www.hindawi.com
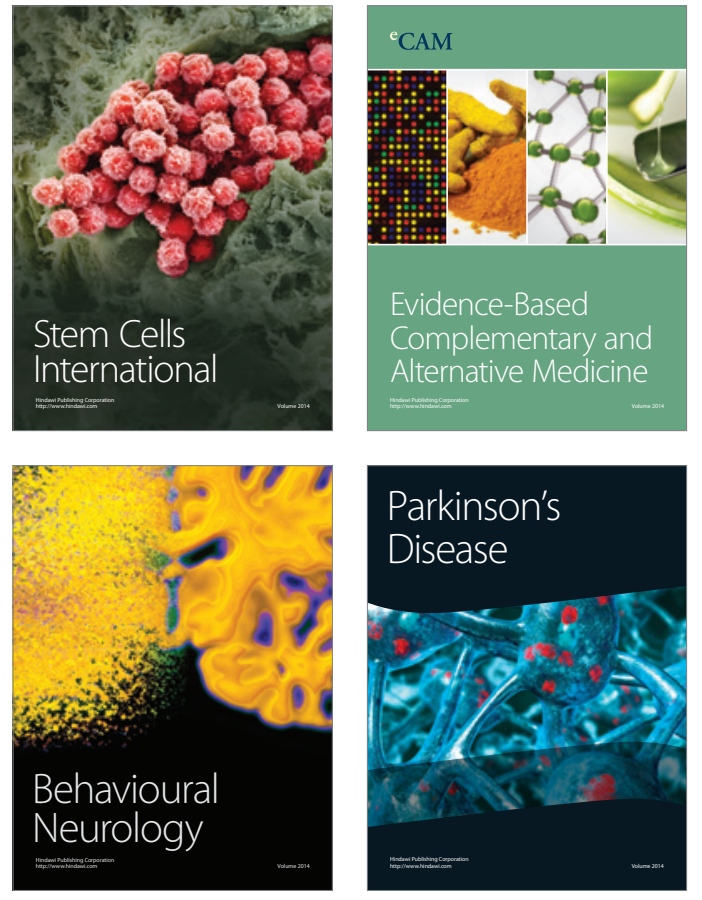
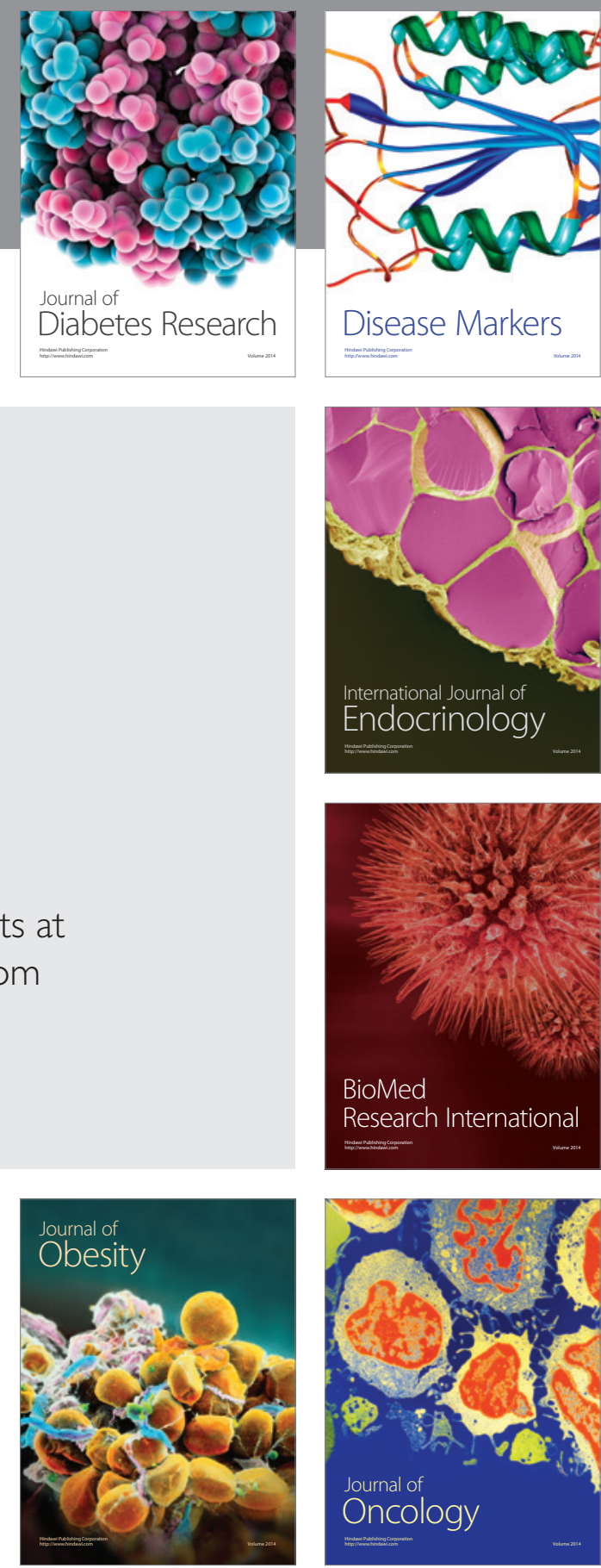

Disease Markers
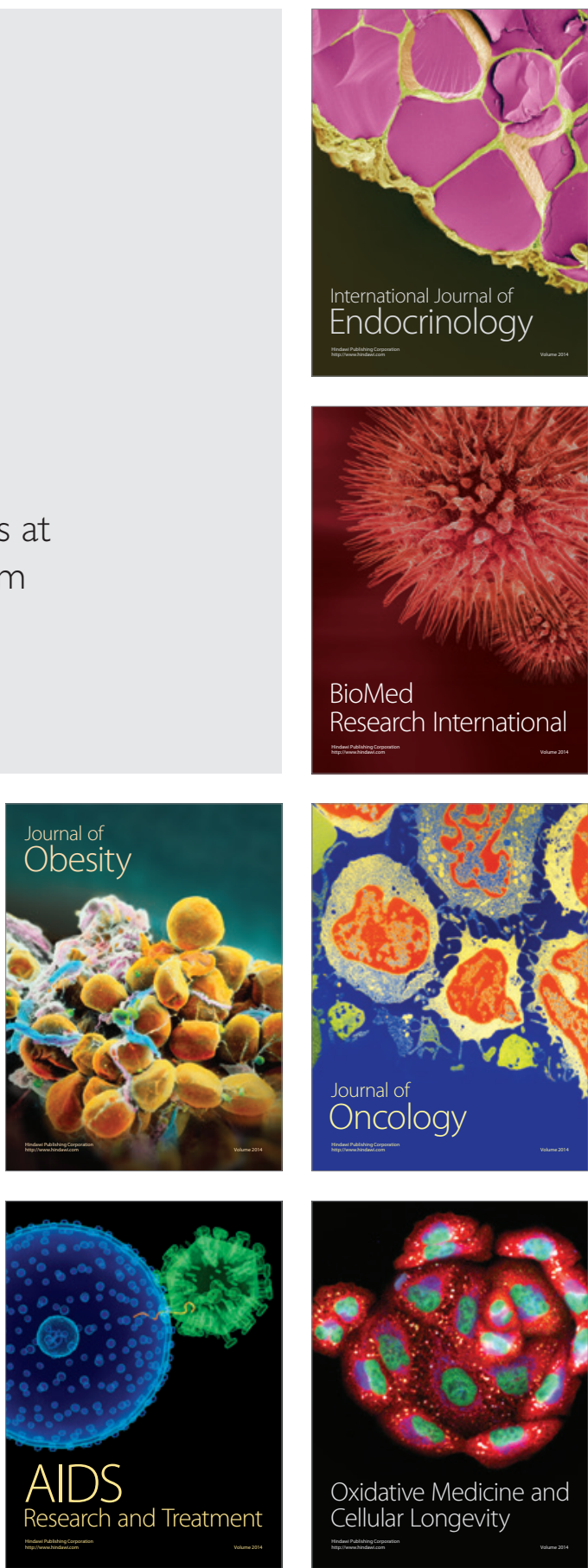